\title{
Musculus Sternalis ve Klinik Önemi
}

\author{
Musculus Sternalis and Clinical Significance
}

Aysun Genç¹, Arda Çetinkaya², Salim Illksen Bașçeken²

Ankara Üniversitesi Haymana Meslek Yüksekokulu, Fizyoterapi Programı

2Uz. Dr. Ankara Üniversitesi Tıp Fakültesi Genel Cerrahi Anabilim Dalı

Geliș tarihi: 04.03.2015 • Kabul tarihi: 09.04.2015

Iletișim

Yrd. Doç. Dr. Aysun Genç

Tel: 03124909028

Faks: 03123103989

E-posta: draysung@yahoo.com

Ankara Üniversitesi Haymana Meslek Yüksekokulu, Fizyoterapi Programı

Musculus sternalis ön göğüs duvarının iyi dökümente edilmiș nadir bir kas varyasyonudur. Pektoral fasia ile yüzeyel fasia arasında uzanan bu kas genel populasyonun \% 8'inde görülmektedir. Kas varyasyonları özellikle insanda boyun gibi çok hareketli ve farklı ișlevler gören kasların olduğu bölgelerde daha sık görülmektedir. Bu tür varyasyonlar genellikle semptomatik bir sıkıntıya yol açmamakla birlikte, kișinin kendisi veya hekim tarafından yanlıșlıkla kitle olarak algılanabilir. Bu yazıda meme kanseri nedeni ile mastektomi uygulanırken tesadüfen saptanan sternal kaslı iki vakayı literatür bilgileri eșliğinde sunduk.

Anahtar Sözcükler: Musculus sternalis, kas varyasyonu, ön göğüs duvarı

The sternalis muscle is a well documented anterior thoracic vall muscle variation. It lies between pectoral and superficial muscles and is detect in about $8 \%$ of the population. Muscle variations are generally seen in neck area because this area muscles has different functions and very mobile. It has generally no symptom but it may perceived as a mass from subject or physician. We report two cases with musculus sternalis that insidentally detected during mastectomy due to breast cancer.

Key Words: Musculus sternalis, muscle variations, anterior thoracic wall

Musculus sternalis ilk kez 1604 yilında Barthelemy Cabrol (Cabrolius) tarafindan cilt ve yă dokusunun altında sternumun yüzeyelinde bir band şeklinde raporlanmiștır (1). 1726 yilinda Du Puy morfolojik olarak detaylı şekilde tanımlamış ve ardından kas ve kasa ait çok sayıda varyasyon literatüre eklenmiştir (2). Turner tarafindan 1867 yılında kasla ilgili yapılan bir çizim Şekil 1'de verilmiştir. Turner bu kası hayvanlarla yaptığı kıyaslamalı anatomik çalışmalar sonucunda panniculus carnosus ad1 verilen ve insanda olmayan bir subkutan doku parças1 ile ilişiklendirmiştir. Evrim teorisinin babası olarak kabul edilen Charles Darwin "The Descent of Man, and Selection in Relation to Sex" isimli kitabında Turner'in bu kas ile ilgili olan fikirlerine de yer vermiştir.

Musculus sternalis kası ve varyasyonları anatomistler tarafindan iyi bilinmesine rağmen klinisyenler ve radyologlar tarafindan aynı ölçüde bilinmemektedir. Kas ayrica presternalis, episternalis, torasik rektus ve rektus sterni adlarıyla da anılmaktadır. Göğüs ön duvarında olması nedeni ile kadınlarda meme dokusu altında kalmakta ve rutin kontroller esnasında çekilen ma- mografi ve/veya meme ultrasonlarinda radyologlar tarafindan farkina varilmaktadir. Ancak bu varyasyonun radyologlar tarafindan bilinmemesi nedeni ile kas göğüs ön duvarında kitle yada asimetrik kas hipertrofisi olarak algilanmakta, ileri görüntüleme yöntemleri hatta gereksiz biyopsiler yapılabilmektedir. Erkeklerde meme kanseri sıklığının az olması nedeniyle ancak jinekomasti operasyonu sirasında geniş diseksiyonlar yapıldığında kas farkedilebilir. Bugüne kadar bildirilmiş kasa bağlı meydana gelen bir semptom olmamıştır dolayısıyla kas ancak radyolojik olarak veya cerrahi esnasinda insidental olarak saptanmaktadir.

Kadeverik incelemelerde musculus sternalisin genel populasyonun yaklaşık \%7.8'inde varolduğu gözlenmiștir. Kişiler arasında olduğu gibi değişik coğrafi bölgelerde de çok sayıda varyasyonu bulunmaktadir. Asya populasyonunda $\% 11.5$, Afrikada $\% 8.4$ ve Avrupada \%4.4 oranında görülmektedir. Ayrıca kadınlarda görülme sıkl1ğ1 (\%8.6) erkeklerden (\%7.5) bir miktar daha fazladır (3). Görüntüleme yöntemleri ile saptanma oranlarının düşük olma nedeni olarak hastanın 
film esnasinda uygun pozisyonda olmamas1, yetersiz rezolusyonlu filmler, radyolog ve klinisyenlerin kasin farkında olmaması gibi nedenler siralanabilir. Standart mamografiler ile saptanma oranlar1 \% 0.018 iken (4), multidetektör bilgisayarlı tomografi ile bu oran $\% 8.4$ lere kadar çıkmaktadır (5).

$\mathrm{Bu}$ çalışmada meme kanseri nedeni ile yapilan cerrahi esnasinda musculus sternalis saptanmış iki olguyu raporladık.

\section{OLGU 1}

72 yaşında kadın hastaya mamografi ve meme ultrasonunda saptanan BIRADS-5 kitle nedeni ile eksizyonel biyopsi ve frozen inceleme yapild. Sonucun malign gelmesi üzerine aynı seansta modifiye radikal mastektomi yapilmasina karar verildi. Ameliyat esnasinda pectoralis major kasindan başlayıp rektus kasında biten ve pectoralis major kasının yüzeyelinde kraniokaudal düzlemde seyreden sternal kas izlendi. Bu kasın saptanması üzerine disseksiyon planı bu kas ile pectoralis major kası arasına doğru ge-

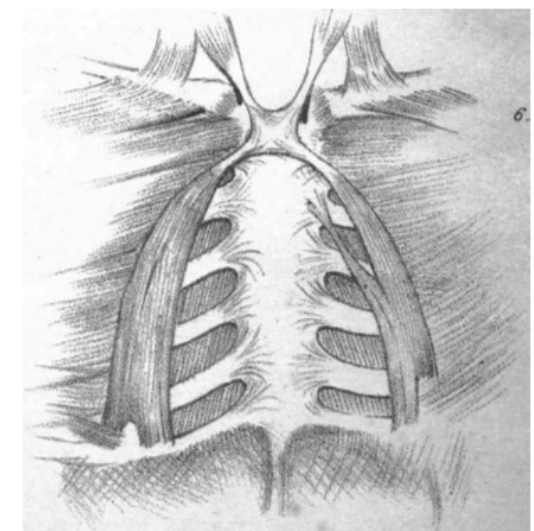

Şekil 1: İki taraflı musculus sternalisin Turner tarafından resmedilen orjinal çizimi (2)

\section{KAYNAKLAR}

1. Eycleshymer AC, Shoemaker DM, Moodie RL. Anatomical Names Especially the Basle Nomina Anatomica. New York: William Wood and Company. $1917 ; 224$

2. Turner W. On the musculus sternalis. J Anat Physiol 1867;1:246-253. nişletilerek ara bağ doku doku çıkarıldı ve aksillar diseksiyon ardından operasyon sonlandırıldı (Şekil 2).

\section{OLGU 2}

52 yaşında kadın hastada mamografide saptanan sağ meme üst iç kadrandaki BIRADS-5 kitleden yapilan tru-cut biyopsi sonucu malign gelmesi üzerine Genel Cerrahi kliniğine yatırıldı. Modifiye radikal mastektomi planlanan hastada ameliyat sirasinda musculus sternalis kasi saptandi. Bu vakada da sternal kas korunarak fascias1 ve çevre bağ dokusu disseksiyon planına dahil edildi (Şekil 3).

Olgu resimlerinde de görüldüğü üzere musculus sternalis ön göğüs duvarında pektoralis major kasının üzerinde uzanan yüzeyel pektoral fasianın üzerinde parasternal bir kitle gibi göze çarpmaktadır. $\mathrm{Bu}$ bazen bir kord uzant1s1, bazen düzgün bir band veya kas (Şekil 2) yada alevimsi, düzensiz kenarlı (Şekil 3) bir şekilde gözlenebilir. Bu kas \%67 unilateral görülmektedir. Kasin üst orijini klavikula alt s1nır1, sternum, sternocleidomastoid

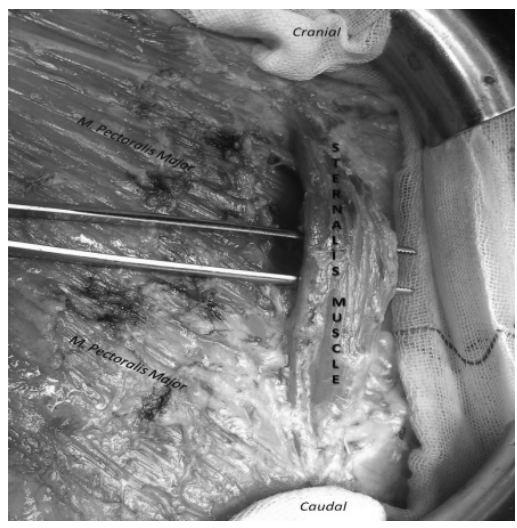

Şekil 2: 76 yaş kadın hastada Modifiye Radikal Mastektomi sırasında saptanan Musculus Sternalis (Mamografi ve ultrasonografide farkedilemem

3. Snosek M, Tubbs RS, Loukas M. Sternalis muscle, what every anatomist and clinician should know. Clinical anatomy 2014;27:866-884.

4. Demirpolat G, Oktay A, Bilgen I, Isayev $H$. Mammographic features of the sternalis muscle. Diagn Interv Radiol 2010;16:276-278. fasia, üst kostalar ya da kostal kartilaj olabilirken alt orijini de alt kostalar ya da kostal kartilajlar, pektoralis major, rektus abdominus kilıfi ya da eksternal abdominal oblik aponevroz olabilir (3). Bizim ilk olgumuzda üst orijin klavikula altı ile sternum, alt orijin pektoralis major kası iken, ikinci olgumuzda ise üst orijin ve alt orijin kostal kartilajlar olarak gözlendi.

Kas pektoral yada interkostal sinirlerce innerve olmaktadır, nadiren her iki sinirden de dallar almaktadır. Kasin bilinen bir fonksiyonu bulunmamaktadır (6). Bu kas ve varyasyonları ile ilgili olgu sunumları kas hakkında farkındalık olușturarak gereksiz yere yapilacak ileri görüntüleme yöntemleri ve/veya biyopsilerin engellenmesine ve gereksiz zaman israfinın önüne geçilmesine yardımcı olacaktır. Meme kanseri cerrahisi esnasinda diseksiyon planlarını değiştireceği için cerrahlar tarafindan da mutlaka bilinmesi gerekmektedir. Ayrica cerrahi esnasinda saptanirsa mutlaka rapor edilmeli ve ileride bu kasın kanser nüksü olarak yorumlanmasının önüne geçilmesi gerekmektedir.

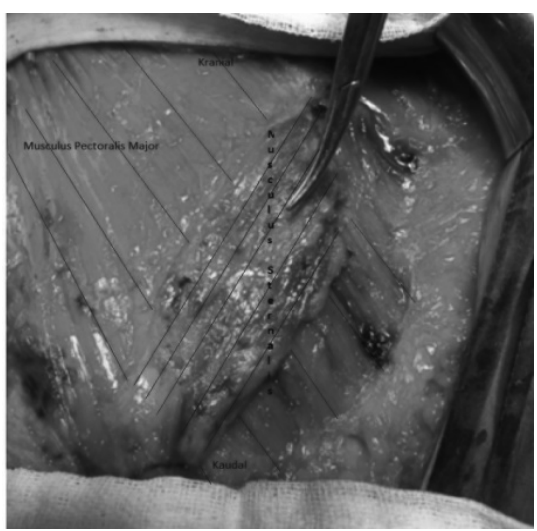

Şekil 3: 52 yaş kadın hastada Modifiye Radikal Mastektomi sırasında saptanan Musculus Sternalis (Mamografi ve ultrasonografide farkedilememiş)

5. Shiotani M, Higuchi $T$, Yoshimura N, et al. The sternalis muscle: Radiologic findings on MDCT. Jpn J Radiol 2012;30:729-734.

6. Hung LY, Lucaciu OC, Wong. Back to the debate: Sternalis muscle. Int J Morphol 2012; 30: 330-336 